\title{
Desain Banyumas Smart City Berbasis Internet of Things (IoT) Menggunakan Fog Computing Architecture
}

\author{
${ }^{1}$ Bayu Prastyo, ${ }^{2}$ Faiz Syaikhoni Aziz, ${ }^{3}$ Wahyu Pribadi, ${ }^{4}$ A.N. Afandi \\ ${ }^{123}$ Pascasarjana Teknik Elektro, Universitas Negeri Malang, Malang \\ ${ }^{4}$ Teknik Elektro, Universitas Negeri Malang, Malang \\ 1bayoe.30015@gmail.com, ${ }^{2}$ faizsyaikhoni@gmail.com, ${ }^{3}$ pakwahyupribadi@gmail.com , ${ }^{4}$ an.afandi@um.ac.id
}

\begin{abstract}
Article Info
Article history:

Received July $19^{\text {th }}, 2020$

Revised August $15^{\text {th }}, 2020$

Accepted September $9^{\text {th }}, 2020$

\section{Keyword:}

Fog Computing

Internet of Things ( IoT)

Smart City.

ABSTRACT

Internet use in Banyumas Regency is now increasingly diverse according to the demands of the needs. The development of communication technology raises various aspects that also develop. For example, the use of the internet for a traffic light control system so that it can be adjusted according to the settings and can be monitored in real time. In the development of communication technology, the term Internet of Things (IoT) emerged as the concept of extending the benefits of internet communication systems to give impulses to other systems. In other words, IoT is used as a communication for remote control and monitoring by utilizing an internet connection. The Internet of Things in the era is now being developed to create an intelligent system for the purposes of controlling various public needs until the concept of the smart city emerges. Basically, smart cities utilize internet connections for many purposes such as controlling CCTV, traffic lights, controlling arm robots in the industry and storing data in hospitals. If the system is carried out directly from the device to the central server, there will be a very long queue of data while the system created requires speed and accuracy of time so that a system is needed that allows sufficient data control and processing to be carried out on network edge users. Then fog Computing is used with the hope that the smart city system can work with small latency values so that the system is more real-time in sending or receiving data.
\end{abstract}

Abstrak—Penggunaan internet di Kabupaten Banyumas kini semakin beragam sesuai dengan tuntutan kebutuhan. Pengembangan teknologi komunikasi menimbulkan berbagai aspek juga ikut berkembang. Sebagai contoh pemanfaatan internet untuk sistem pengendalian lampu lalu lintas agar dapat diatur sesuai dengan pengaturan dan dapat dimonitoring secara real time. Dalam perkembangan teknologi komunikasi, muncul istilah Internet of Things (IoT) sebagai konsep memperluas manfaat dari system komunikasi internet untuk memberikan impuls pada suatu system yang lain. Dengan kata lain, IoT dimanfaatkan sebagai komunikasi untuk kendali dan monitoring jarak jauh dengan memanfaatkan koneksi internet. Internet of Things di era sekarang sedang dikembangkan untuk membuat sebuah system cerdas untuk keperluan pengendalian berbagai keperluan public hingga muncul konsep smart city. Pada dasarnya, smart city memanfaatkan koneksi internet untuk banyak keperluan seperti mengendalikan CCTV, lampu lalu lintas, pengendalian robot lengan pada industry dan penyimpanan data pada rumah sakit. Bila system tersebut dilakukan secara langsung dari device ke server pusat maka akan terjadi antrian data yang sangat panjang sedangkan system yang dibuat menuntut kecepatan dan keakuratan waktu sehingga dibutuhkan sebuah sistem yang memungkinkan pengendalian dan pemrosesan data cukup dilakukan pada network edge pengguna. Maka digunakanlah fog computing dengan harapan system smart city mampu bekerja dengan nilai latency yang kecil sehingga system lebih real time dalam mengirim atau menerima data.

Kata Kunci- Fog Computing, Internet of Things ( IoT), Smart City.Pendahuluan

\section{Pendahuluan}

Penggunaan internet sudah menjadi hal lumrah di kehidupan sekarang ini. Banyak sekali pengguna yang memanfaatkan internet sebagai media komunikasi maupun pengembangan dalam bidang tertentu yang berkaitan dengan teknologi komunikasi. Sebagai contoh BMKG yang memanfaatkan komunikasi internet untuk menerima data dari aktuator suhu, kelembapan, atau seismograf. Teknologi komunikasi kini semakin berkembang dengan munculnya gagasan Internet of Thing (IoT) sebagai solusi untuk pengendalian atau menghubungkan berbagai device. 
Internet of Thing (IoT) adalah sebuah teknologi yang dapat menghubungkan segala jenis device [1]. Internet of Thing (IoT) menawarkan beragai macam desain komunikasi untuk proses pengendalian, monitoring, dan pengaturan dengan memanfaatkan komunikasi internet. Penggunaan Internet of Things makin berfariatif sejalan dengan perkembangan teknologi. Salah satu pemanfaatan IoT adalah smart city.

Di kabupaten Banyumas terdapat berbagai fasilitas publik yang dirasa perlu untuk dikembangkan menggunakan Internet of Things karena akses tiap fasilitas publik yang sangat jauh dan tingkat pembangunan pariwisata yang mulai berkembang sehingga dibutuhkan sistem yang mempermudah untuk mengakses fasilitas publik atau mengendalikan kebutuhan publik.

Smart city adalah sebuah sistem yang menggunakan teknologi untuk menyelesaikan berbagai masalah seperti kemacetan jalan raya, keamanan umum, konsumsi energi, sanitasi, dan koneksi internet umum [2]. Teknologi smart city diproyeksikan menjadi mesin ekonomi besar dalam dekade mendatang, dan diperkirakan akan bernilai kumulatif 1,565 triliun dolar pada 2020, dan 3,3 triliun dolar pada 2025 [3].

Namun pada smart city yang menggunakan IoT mempuyai beberapa masalah yaitu harus menyebarkan perangkat IoT ke wilayah geografis yang luas [4]. Strategi seperti itu mungkin terbukti sangat mahal. Misalnya, dalam kasus penerangan jalan, setiap tiang lampu akan dilengkapi dengan sensor dan antarmuka komunikasi. Untuk kota besar dengan beberapa ribuan tiang lampu yang tersebar di area yang luas, menambahkan perangkat IoT ke setiap tiang lampu dapat memaksakan biaya penerapan dan perawatan yang signifikan. Salah satu alternatifnya adalah menerapkan jaringan sensor nirkabel mobile yang mencakup seluruh wilayah yang diminati [5].

Pada perangkat IoT memiliki kemampuan pemrosesan dan penyimpanan yang terbatas, sementara aplikasi smart city mengumpulkan dan menganalisis data yang besar [5]. Dengan demikian, solusi untuk menyimpan dan memproses data yang terkumpul adalah dengan menggunakan cloud computing. Perangkat IoT bertanggung jawab untuk merasakan dan aktuasi, sementara tugas pemrosesan yang lebih berat dilakukan oleh cloud computing, yang memiliki kekuatan pemrosesan lebih banyak dan mampu mengumpulkan semua data.

Namun, pada pusat data di cloud computing menghadapi masalah yang besar pada jumlah data yang meledak, latency, antrian data, dan jarak device yang terlalu jauh dari pusat data. Maka perlu sebuah sistem yang memungkinkan sistem tidak melalui pusat data untuk mengirim data dengan device yang diketahui menggunakan fog computing. Oleh sebab itu dalam paper ini, membahas Desaian Banyumas Smart City Berbasis Internet of Things (IoT) Menggunakan Fog Computing Architecture.

\section{Metode penelitian}

Metode Penelitian dalam Desain Banyumas Smart City Berbasis Internet of Things (IoT) Menggunakan Fog Computing Architecture menawarkan sebuah kajian desain yang sangat layak dipertimbangkan dalam implementasi karena hasilnya diharapkan dapat lebih memuaskan dengan konsep baru yang ditawarkan. Gambar 1 menunjukan diagram alur penelitian dan pembuatan desain smart city.

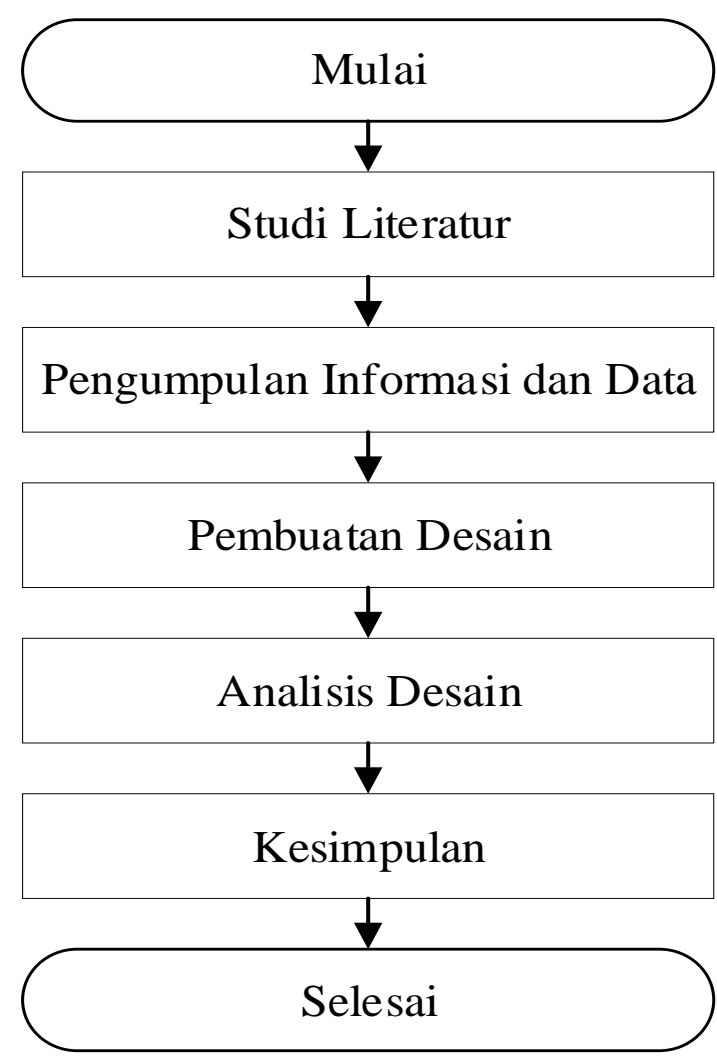

Gambar 1. Diagram Alur Penelitian

\section{Hasil Desain dan Pembahasan}

Berdasarkan studi literatur dan pengumpulan informasi. Hasil desain smart city akan dibagi menjadi dua bagian yaitu desain smart city perbidang dan desain arsitektur banyumas smart city pada semua bidang .

\section{A. Desain Smart City Perbidang}

Desain banyumas smart city yang dikembangkan dalam paper ini adalah 4 bidang antara lain : Intelligent Hospital Integrated System, Intelligent PDAM Integrated System, Intelligent Traffic Integrated System dan Intelligent Grid Integrated System.

1) Desain Intelligent Hospital Integrated System (IHIS)

Kebutuhan akan kesehatan menuntut rumah sakit untuk lebih berkembang khususnya dalam hal informasi. Ketersediaan ruang, darah, obat dan kemampuan tiap rumah 
sakit dalam menangani pasien perlu dikordinasikan, baik dalam 1 kompleks rumah sakit maupun rumah sakit se-Kabupaten Banyumas.

Kabupaten Banyumas memiliki banyak rumah sakit dengan letak geografis yang berbeda-beda dan juga dengan kemampuan yang berbeda-beda [6]. Kebutuhan akan komunikasi antar rumah sakit perlu ditingkatkan untuk mengetahui rumah sakit mana yang membutuhkan darah, obat atau bantuan tenaga medis. Selain itu masyarakat juga membutuhkan informasi yang sama agar lebih cepat tanggap menyelesaikan masalah kesehatan. Teknologi Internet of Things bisa dikembangkan sebagai sistem informasi antar blok dalam satu komplek rumah sakit maupun antar rumah sakit.

Di Kabupaten Banyumas terdapat 6 rumah sakit yang dijadikan sebagai contoh kordinasi rumah sakit berdasarkan letak geografis dan mata angin [6]. Rumah sakit yang dijadikan subjek uji coba dapat dilihat pada tabel 1 .

Tabel 1. Daftar Rumah Sakit Subjek Uji Coba

\begin{tabular}{|l|l|l|}
\hline No & Rumah Sakit & Letak \\
\hline 1 & RSUD Ajibarang & Barat Laut \\
3 & RS Santa Elisabeth & Utara \\
4 & RSUD Banyumas & Timur Laut \\
5 & RSU Medika & Tenggara \\
6 & Klinik Wisnu Husada & Selatan \\
\hline
\end{tabular}

Setiap rumah sakit akan mengirimkan informasi menggunakan jaringan fog computing dan juga akan ada peringatan bila terdapat rumah sakit yang membutuhkan parameter yang dikirimkan rumah sakit. Selain itu, masyarakat juga dapat memantau informasi parameter yang dikirmkan melalui smartphone.

Desain arsitektur dari fog computing untuk Banyumas smart hospital dapat dilihat pada gambar 2.

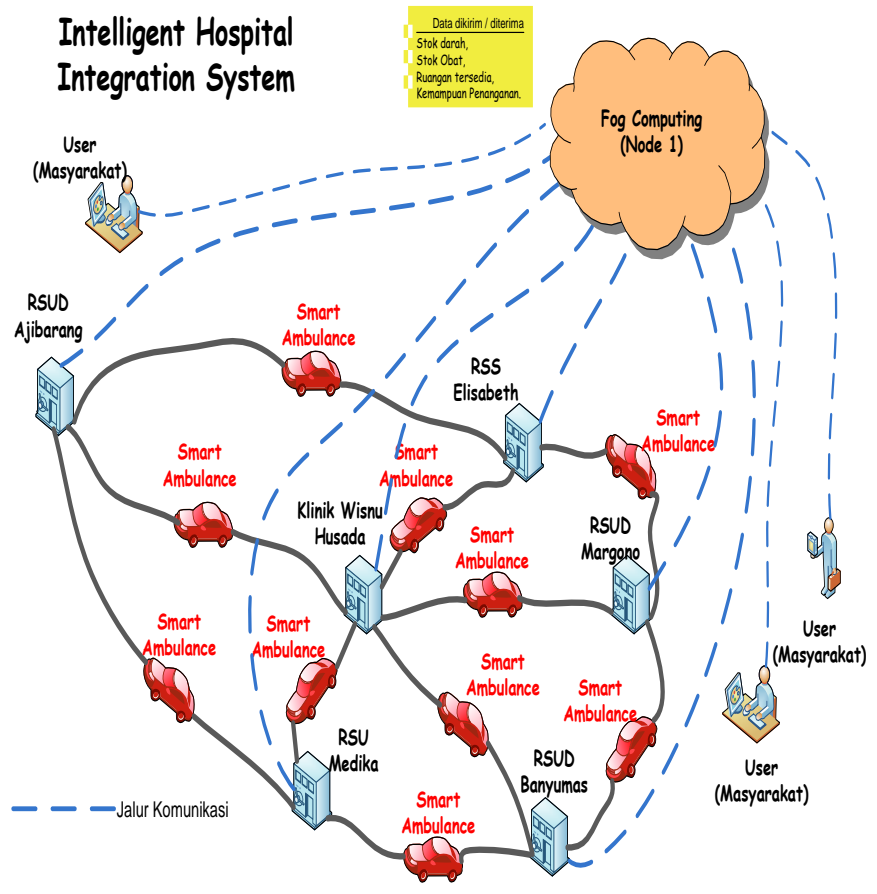

Gambar 2. Desain Arsitektur Intelligent Hospital Integration System

2) Desain Intelligent PDAM Integrated System (IPAM)

Kebutuhan yang harus selalu tersedia selalu listrik adalah penyediaan air minum. Ketersediaan air bersih di Indonesia dijamin oleh Perusahaan Daerah Air Minum atau PDAM. Dalam penyediaan air bersih, PDAM dituntut untuk terus menyuplai air bersih secara steady state tanpa ada nilai fluktuatif debit air maupun kualitas air. Memanfaatkan teknologi Internet of Things, PDAM mampu mengendalikan aliran air agar selalu steady state dengan kualitas air yang baik pula.

Kabupaten Banyumas didesain memiliki 6 PDAM dengan posisi yang saling berjauhan dan setiap PDAM melayani tiap wilayah [7]. Nama 6 PDAM tersebut dapat dilihat pada tabel 2.

Tabel 2. Daftar PDAM Subjek Uji Coba

\begin{tabular}{|l|l|l|}
\hline No & Rumah Sakit & Letak \\
\hline 1 & PDAM Tirta Satria BMS 1 & Utara \\
2 & PDAM Tirta Satria BMS 2 & Timur Laut \\
3 & PDAM Tirto Satria Purwojati & Barat \\
4 & PDAM Kejawar & Selatan \\
5 & PDAM Sokaraja & Timur \\
6 & PDAM Unit Cabang PWT & Tengah \\
\hline
\end{tabular}


Aliran air di setiap wilayah terhubung dan dikendalikan oleh PDAM tiap wilayah dengan bantuan teknologi smart valve. Tujuan pemasangan smart valve adalah untuk mengatur interkoneksi tiap wilayah sehingga ketika salah satu PDAM mengalami krisis air maka PDAM lain mampu mem back-up suplai air sehingga debit air yang didistribusikan tetap sama.

Selain itu, tiap PDAM mampu mengatur kualitas air dengan bantuan teknologi smart water quality dengan tujuan memantau kualitas air, sehingga bila kualitas air menurun maka air akan diarahkan ke tandon pembersih,

Desain arsitektur dari Intelligent PDAM Integrated System bisa dilihat pada gambar 3 .

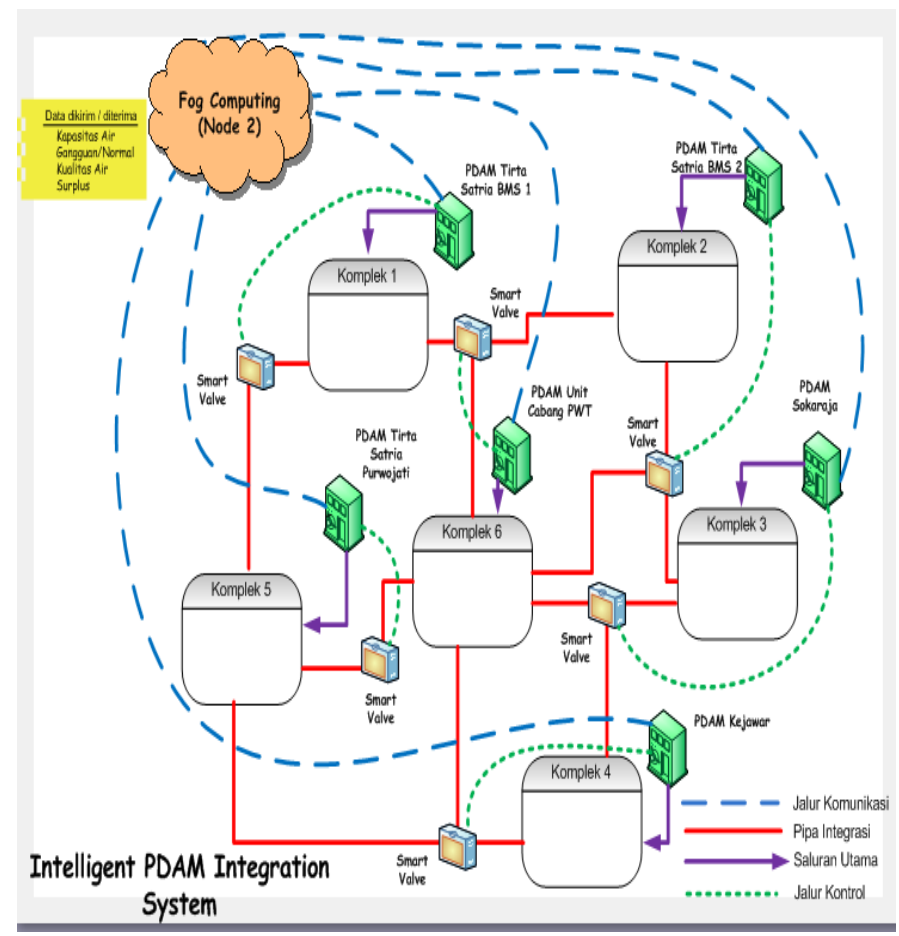

Gambar 3. Desain arsitektur Intelligent PDAM Integration System

3) Desain Intelligent Traffic Integrated System (ITIS)

Perkembangan transportasi mulai mengarah ke sistem berbasis smart. Beberapa pengembangan sudah mengarah ke smart car yang mampu berkendara tanpa harus dikemudikan. Dengan penggunaan banyak sensor menjadikan smart car bisa dimanfaatkan dengan memadukannya ke smart traffic. Teknologi smart traffic memungkinkan persimpangan jalan bisa mengatur sendiri aliran kendaraan dengan parameter kepadatan dan kecapatan smart car.

Setiap persimpangan saling berkomunikasi untuk mengatur aliran kendaraan memanfaatkan fog computing tanpa harus mengirim ke cloud. Tempat yang akan dijadikan sebagai percontohan model adalah simpangan di Jalan Jendral Soedirman dengan bentuk arsitekturnya dapat dilihat pada gambar 4.

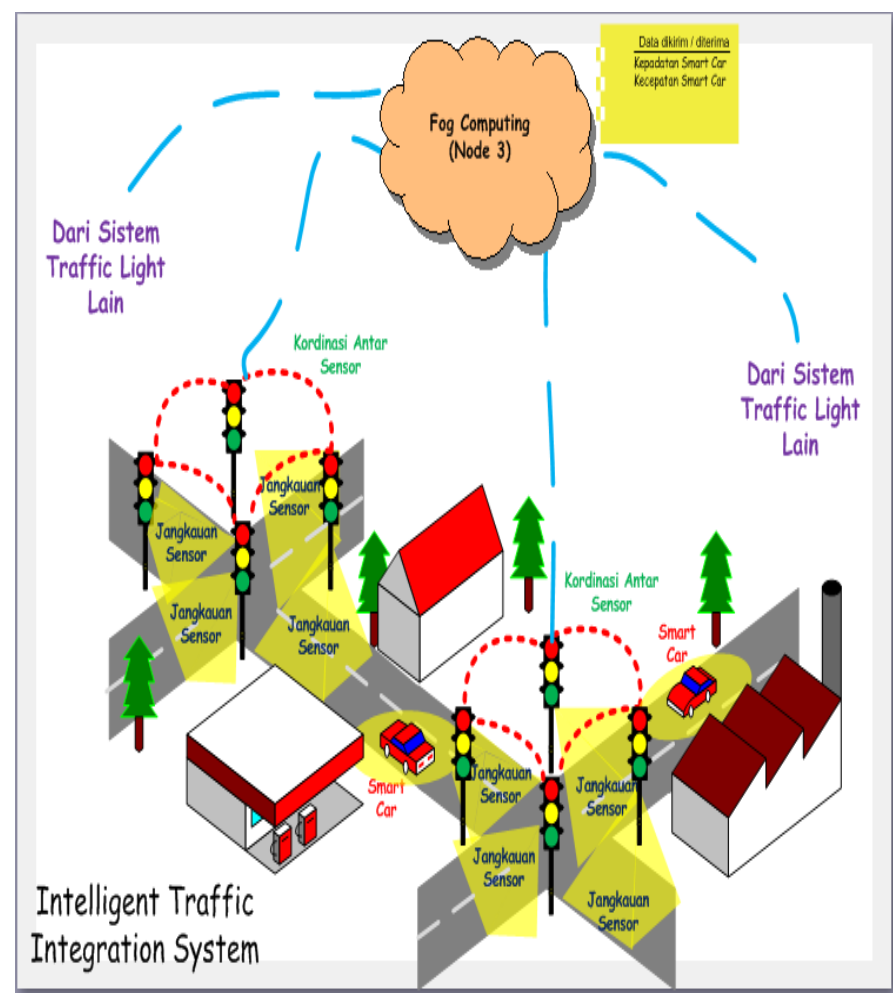

Gambar 4. Desain Arsitektur Intelligent Traffic Integration System

\section{4) Desain Intelligent Grid Integrated System (IGIS)}

Listrik sudah menjadi kebutuhan sehari-hari masyarakat, khususnya di Kabupaten Banyumas. Kebutuhan listrik di kabupaten Banyumas mulai meningkat seiring dengan makin berkembangnya pariwisata dan ekonomi. Banyak sekali pariwisata yang mengharuskan mendapat suplai listrik dalam kapasitas yang besar dan stabil. Maka dari itu di Kabupaten Banyumas mulai dibangun PLTPB di area Gunung Slamet sebagai sumber tambahan bagi pelanggan listrik.

Banyumas memiliki 1 PLTA aktif, yaitu PLTA Ketenger dan menyuplai langsung ke Gardu Induk Kalibakal Purwokerto. Selain itu, Banyumas juga mendapat suplai langsung dari PLTA Cilacap (dalam 2 jaringan) dan berinterkoneksi dengan Gardu Induk Rawalo yang juga mendapat suplai dari PLTA Cilacap serta Gardu Induk Bumiayu (di luar Kabupaten).

Dengan system yang ada sekarang ini masih dianggap cukup untuk memenuhi kebutuhan listrik Banyumas. Namun dengan perkembangan Banyumas yang cepat, di masa depan kebutuhan listrik tidak akan cukup bila menggunakan system yang sama. Maka dari itu dikembangkan Intelligent Grid Integrated System dengan gagasan smart grid untuk menambahkan sumber-sumber alternative yang berpotensi di Banyumas, yaitu panel surya, mikrohidro, dan panas bumi dari gunung slamet ke sistem jaringan kelistrikan utama.

Smart Grid adalah infrastruktur jaringan listrik modern untuk meningkatkan efisiensi, keandalan dan keselamatan, dengan integrasi yang mulus dari sumber energi terbarukan 
dan alternatif, melalui kontrol otomatis dan teknologi komunikasi modern[8,9]. Sistem Smart Grid akan digunakan di Kabupaten Banyumas dengan memanfaatkan potensi sumber renewable energy yang sesuai dengan kondisi lingkungan. Sistem yang dirancang selanjutnya diberi nama Intelligent Grid Integrated System.

Intelligent Grid Integrated System adalah gagasan smart grid yang mengendalikan 8 pusat penyuplai listrik dan pengendali aliran listrik. Delapan device ini dapat dilihat pada Tabel 3.

\begin{tabular}{|l|l|l|} 
Tabel 3. Device pada Intelligent Grid Integrated System \\
\hline No & Device & Letak \\
\hline 1 & PLTU Cilacap & Barat Daya \\
2 & Gardu Induk Kebasen & Barat \\
3 & PLTA Mikrohidro & Barat laut \\
4 & PLTPA Gunung Slamet & Utara \\
5 & PLTA Ketenger & Timur Laut \\
6 & Gardu Induk Kalibakal & Tenggara \\
7 & Smart Home & Menyebar \\
\hline
\end{tabular}

Prinsip kerja dari Intelligent Grid Integrated System adalah dengan mengendalikan aliran daya listrik dari beberapa sumber pembangkit fosil yang dibantu oleh pembangkit nonfosil. Semua aliran daya diatur oleh smart grid control berdasarkan data-data yang dikirimkan oleh tiap pembangkit, gardu induk dan smart home sebagai konsumen ke fog computing. Ketika pembangkit fosil mengalami undervoltage atau underfrequency maka secara otomatis smart grid control akan mengirimkan data ke pembangkit non-fosil untuk ikut membantu penyaluran. smart grid control juga akan memberikan informasi kepada smart home untuk menggunakan self PV atau panel surya penggunaan sendiri sebagai sumber listrik smart home sehingga beban dapat berkurang sehingga perbaikan tegangan dan frekuensi bisa dipercepat. Arsitektur dari Intelligent Grid Integration System dapat dilihat pada gambar 5 .

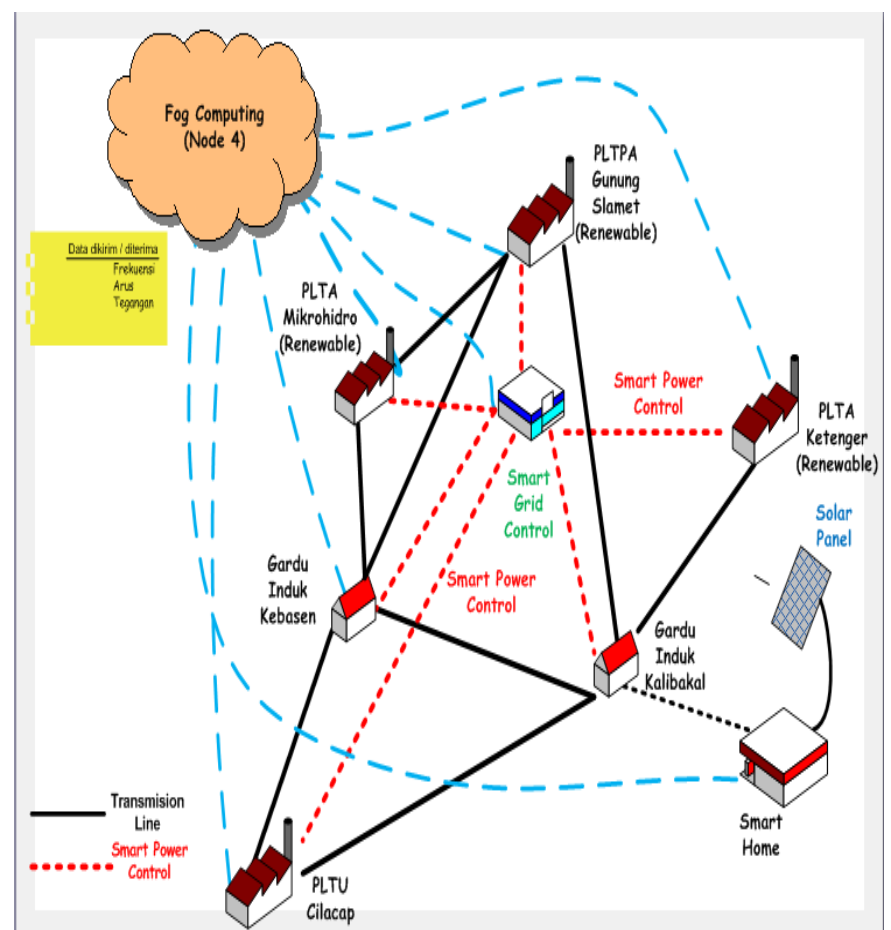

Gambar 5. Desain Arsitektur Intelligent Grid Integration System

\section{B. Desain Arsitektur Banyumas Smart City}

Banyumas sebagai salah satu kabupaten yang memiliki potensi pariwisata dan perkembangan ekonomi perlu mempersiapkan diri untuk revolusi Industri 4.0. Beberapa sistem smart city kini mulai dikembangkan dengan menggunakan IoT sebagai teknologi komunikasinya. Beberapa desain dari sub-sistem sudah mulai dibuat meski baru mecakup beberapa tempat. Dengan desain dari tiap sub smart city, maka dapat dibuat sebuah arsitektur Banyumas smart city yang saling berintegrasi bertukar data. Desain Arsitektur dari Banyumas smart city dapat dilihat pada gambar 6. 


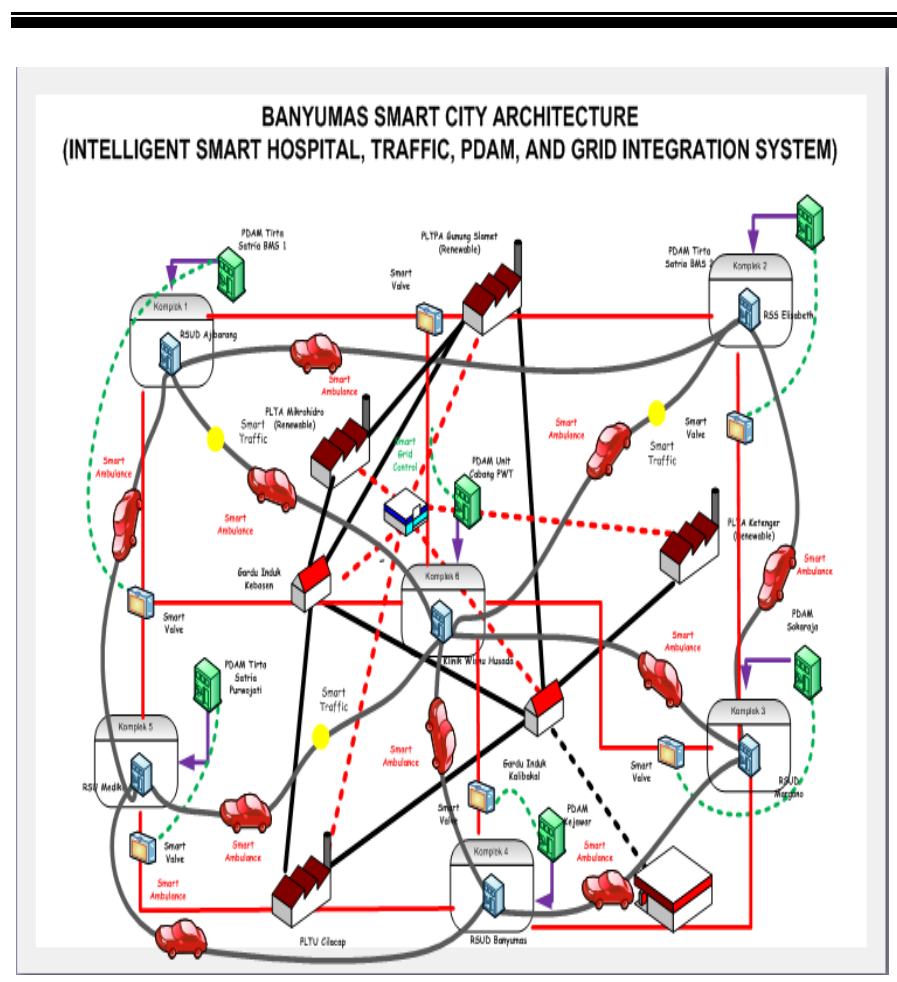

Gambar 6. Arsitektur Banyumas Smart City

Setiap fog node dari sub-smart city akan dihubungkan ke cloud computing dan mengirimkan atau menerima data yang diperlukan. Setiap fog node juga saling berbagi informasi sesuai kebutuhan dengan contoh sebagai berikut.

1) Smart Ambulance membutuhkan akses cepat untuk sampai ke rumah sakit, maka smart ambulance bisa mengakses sistem dari ITIS untuk mempermudah ambulance untuk lewat tanpa hambatan lalu lintas.

2) Sistem dari smart traffic membutuhkan suplai listrik yang stabil. Saat listrik untuk smart traffic kualitasnya memburuk, maka ITIS akan mengirim permintaan perbaikan kualitas listrik ke IGIS melalui smart grid control.

3) System dari IHIS membutuhkan beberapa data dari kestabilan kualitas air agar kebersihan alat-alat kesehatan makin terjamin. Maka system IHIS akan meminta data kepada IPIS dan melaporkan bila terjadi penurunan kualitas air PDAM.

Selain hubungan antara sub-sistem smart city atau antar fog node ke fog node lain, terdapat hubungan antara fog dan cloud computing. Hubungan ini memungkinkan system smart city berbasis fog dapat mengirimkan beberapa data ke cloud dengan beberapa tujuan tertentu, seperti untuk penyimpanan, penelitian, atau untuk dihubungkan ke pengguna cloud secara langsung.

Desain hubungan fog dan cloud computing bisa dilihat pada gambar 7 .

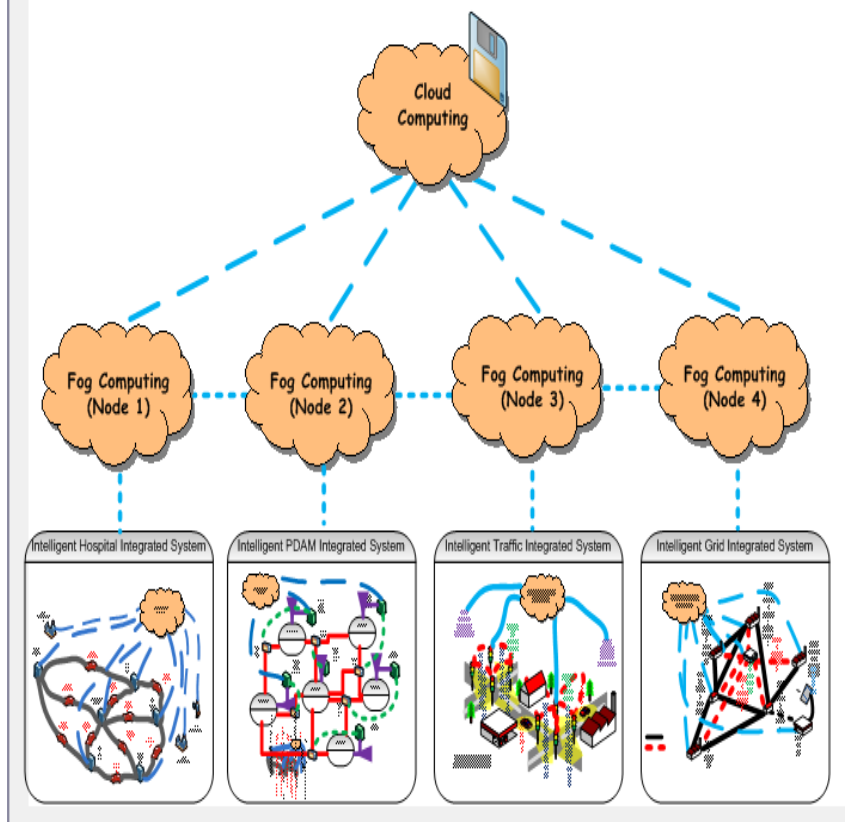

Gambar 7. Hubungan Fog dan Cloud Computing Banyumas Smart City

\section{Kesimpulan}

Kesimpulan dari Desain Banyumas Smart City Berbasis Internet of Things (IoT) Menggunakan Fog Computing Architecture sebagai berikut.

1. Banyumas sebagai kabupaten berkembang membutuhkan berbagai system yang saling terintegrasi.

2. Internet of Things dipilih dengan menggunakan fog computing untuk mengurangi latensi, mempermudah komunikasi antara pusat device dengan sensor-sensor yang jaraknya sangat jauh, dan menghindari antrian data yang terjadi di cloud.

3. Konsep yang dibuat adalah dengan membuat Banyumas Smart City.Konsep yang dibuat hanya membuat arsitektur 4 sub-smart city yaitu rumah sakit, PDAM, lalu lintas, dan jaringan listrik.

4. Kedepannya, penelitian ini dapat dikembangkan dengan menambahkan system kendali atau algoritma parameter yang digunakan pada tiap sub-smart city.

\section{Daftar Pustaka}

[1] Benazzouz. Y, Munilla. C, Gunalp. O, Gallissot. M, Gurgen . L, "Sharing User IoT Devices in the Cloud" in IEEE World Forum on Internet of Things (WF-IoT), pp. 373-374, 2014.

[2] IEEE Standard for Adoption of OpenFog Reference Architecture for Fog Computing," in IEEE Std 19342018 , vol., no., pp.1-176, 2 Aug. 2018.

[3] Tang. B, Chen. Y, Hefferman. G, Pei. S, Wei. T, Yang. Qing "Incorporating Intelligence in Fog Computing for 
Big Data Analysis in Smart Cities" in IEEE Transactions on Industrial Informatics, pp. 1-11, 2016.

[4] Sadiyanto, Profil Kesehatan Kabupaten Banyumas Tahun 2015, 2015, (online), (http://www.depkes.go.id/ resources/download/profil/profilkabkota2015/3302jaten gkabbanyumas_2015), diakses 10 April 2019.

[5] https://pdambanyumas.com, diakses 10 April 2019.

[6] V. C. G“ung“or, D. Sahin, T. Kocak, S. Erg“ut, C. Buccella, C. Cecati, and G. P. Hancke, "Smart grid technologies: communication technologies and standards," IEEE transactions on Industrial informatics, vol. 7, no. 4, pp. 529-539, 2011.

[7] W. Su, H. Eichi, W. Zeng, and M.-Y. Chow, "A survey on the electrification of transportation in a smart grid environment," IEEE Transactions on Industrial Informatics, vol. 8, no. 1, pp. 1-10, 2012.

[8] H. Chourabi, T. Nam, S. Walker, J. R. Gil-Garcia, S. Mellouli, K. Nahon, T.A.Pardo, and H.J.Scholl, "Understanding smart cities: Anintegrative framework," in International Conference on System Science (HICSS), pp. 2289-2297, 2012.

[9] IEEE Standard for Adoption of OpenFog Reference Architecture for Fog Computing," in IEEE Std 19342018 , vol., no., pp.1-176, 2 Aug. 2018 